\title{
Experimental Investigation of Land Mobile Prediction Methods and Modeling of Radio Planning Tool Parameters along Indian Rail Road Rural Zones
}

\author{
M. V. S. N. Prasad, ${ }^{1}$ P. K. Dalela, ${ }^{2}$ and M. Chaitanya ${ }^{3}$ \\ ${ }^{1}$ National Physical Laboratory, Dr. K. S. Krishnan Road, New Delhi 110012, India \\ ${ }^{2}$ Wireless Group, Centre for Development of Telematics (C-DOT), Mandigaon Road, Opposite New Manglapuri, \\ Chattarpur, Mehraulli, New Delhi 110030, India \\ ${ }^{3}$ Department of Computer Science, School of Computing and Electrical Engineering, University of Missouri, \\ Kansas City, MO 64110, USA
}

Correspondence should be addressed to M. V. S. N. Prasad, mvsnprasad@gmail.com

Received 26 December 2007; Revised 15 April 2008; Accepted 8 June 2008

Recommended by A. Panagopoulos

\begin{abstract}
Mobile communication networks in rural zones were not given enough importance and emphasis unlike their urban counter parts due to the unattractive revenues and economic considerations for the cellular operators. In order to identify the suitable prediction methods for Indian rail road rural zones, train-based measurements were conducted in the northern and western rural zones along rail roads. These were carried out by recording the carriers emitted by the trackside base stations inside the moving train. The observed signal levels converted into path losses were compared initially with various conventional prediction methods. The observed results were also compared with the predicted results of radio planning tool utilizing digital terrain data. The constants of the model incorporated in the radio planning tool were tuned separately for north Indian and west Indian base stations based on the observed results. The suitability of the models has been evaluated in terms of standard statistical parameters.
\end{abstract}

Copyright ( $) 2008$ M. V. S. N. Prasad et al. This is an open access article distributed under the Creative Commons Attribution License, which permits unrestricted use, distribution, and reproduction in any medium, provided the original work is properly cited.

\section{INTRODUCTION}

The deployment of future mobile communication systems requires accurate planning tools for efficient performance. A knowledge of suitable prediction method helps to optimize the signal levels and reduces interference to neighboring users. A single prediction might not be suitable over India since it is a vast country with diverse topographic and environmental features. Some of the urban regions have non uniform building structure and some of the rural regions have difficult terrains. To identify the prediction method suitable for a given region, a good number of experimental campaigns are necessary and evaluation of various prediction methods against these observed results gives an insight into the suitability of these methods and the possibility of transporting these methods to similar regions of the country. In rural environments where there is varying tree density and terrain is irregular, it is difficult to have links with long distances, good data rate, and line-of-sight mode [1]. It is better to investigate with the help of experimental observations the extent of line-of-sight (los) and non-los zones and the associated problems. Organizations like Universal Services Obligation Fund Administration are funding projects in rural India for shared infrastructure for establishing cellular mobile telephone services. In this context, identifying methods relevant to rural zones and modifying the existing prediction methods in terms of tuning the coefficients are the need of the hour.

Medeisis and Kajackas [2] presented the comparison of Hata model with measurements in urban and rural zones at Lituania at 160, 450, 900, and $1800 \mathrm{MHz}$ bands. In the urban region, the standard deviation of Okumara-Hata method was in the range of 5-7 dB. Best precision of Okumara-Hata model in urban areas was achieved in the $900 \mathrm{MHz}$ range. In the rural areas, measured results deviated significantly from the model. Here the standard deviation increased up 
to $15 \mathrm{~dB}$ and more. Only in the $160 \mathrm{MHz}$ band model and experiments agreed very well. Blaunstein and Ben-Shimol [3] studied theoretically and experimentally the frequency dependence of path loss for various terrestrial macrocell and microcell environments. They have deduced various algorithms for link budget designs suggesting modifications like additional diffraction coefficient, effective height parameter. Miyashita et al. [4] conducted field measurements in eleven areas in Japan including urban, rural, mountainous, and water areas and investigated diffraction, Okumura-Hata and two ray models. The models are selected depending on the terrain between transmitter and receiver. They have deduced correction factors based on the features of each path loss model and authors claim that proposed method gives a good level of accuracy compared to that of conventional models.

\section{EXPERIMENTAL DETAILS}

Keeping the above objective in view, in the present study a comparison of different prediction methods used for land mobile radio in rural/suburban areas has been carried out utilizing UHF train mobile radio measurements conducted in the northern and western regions of the country. The track side base stations utilized in the study are (1) Meerut, (2) Muzzafarnagar, (3) Saharanpur located in northern India (1) Vangani, (2) Neral, (3) Karjat, (4) Pangoli (5) Talegaon, and (6) Pune situated in western India. The base stations in northern India are located at $40 \mathrm{~m}$ above ground level and those in western India are situated at 26, 25, 60, 46, 115, and $45 \mathrm{~m}$ above ground level. The effective radiated powers of the base stations which are Meerut, Muzzafarnagar, Saharanpur, Vangani, Pangoli, and Pune are $+37 \mathrm{dBm}$, whereas those of Neral, Karjat, and Talegaon are $+39.5 \mathrm{dBm}$. The checking of transmitter power, frequency, VSWR, and supply voltage was done regularly to monitor the deviations, and the values of the parameters reported in the paper are correct to the best of our knowledge.

At the time of measurements, Indian railways were allocated frequency range from 314 to $322.6 \mathrm{MHz}$. Train radio network occupies a bandwidth of $2 \times 850 \mathrm{kHz}$, in the range from 314 to $314.85 \mathrm{MHz}$ and 321.0 to $321.85 \mathrm{MHz}$. Base stations located along the track continuously transmit the carrier at $320 \mathrm{MHz}$. In this carrier band, the bandwidth is $850 \mathrm{kHz}$. A test coach is equipped with a calibrated receiver and computerized data logger. Also a chart recorder was used to record the carrier levels. To relate path loss values with locations, a counter of wheel rotations was necessary to drive the paper chart in a fixed linear relation to the train speed as well as having the option of storing samples at selectable intervals. The receiver sensitivity will be better than $0.5 \mu \mathrm{v}(-93 \mathrm{dBm})$ for $20 \mathrm{dBS} / \mathrm{N}$ ratio measured at an RF signal modulated with $1000 \mathrm{~Hz}$ at $60 \%$ of the peak deviation into the duplexer antenna input. The dynamic adjacent channel selectivity will be $70 \mathrm{~dB}$ or better. A low profile omnidirectional antenna was used for reception at the roof of the coach. Slight directing antenna radiation patterns have been used for reduction of radiation in unwanted direction and obtain moderate antenna gain of $5 \mathrm{~dB}$. Slightly directional antennas have been employed when the track has minimum number of turns. Track is a broad gauge type with width of $1.676 \mathrm{~m}$. Highly directional antennas have been employed when the track is straight and omnidirectional antennas are employed when the track is zigzag and with a large number of turns. However, in the present case of slightly directional antennas, the beam width corresponded to $88^{\circ}$ in horizontal direction and $30^{\circ}$ in vertical direction.

Antennas are vertically polarized, $50 \mathrm{ohms}$ impedance. VSWR is less than 1.5:1 across the frequency band with antenna gain of $5 \mathrm{~dB}$, branching and feeder loss of transmitter cable is $3 \mathrm{~dB}$, receiving antenna gain is $0 \mathrm{~dB}$ and omnidirectional, and branching and feeder loss of receiver cable is $1 \mathrm{~dB}$.

\subsection{Data processing}

The signal is measured at a distance of every meter and is averaged over a distance of hundred meters. Here $90 \%$ coverage implies an uncovered track of $10 \mathrm{~m}$ track. This averaged signal is converted into path loss values and its standard deviation, maximum value, and minimum values were deduced. The coverage is calculated by division of the number of samples exceeding threshold by the total number of samples. This experiment was primarily conducted by Indian railways mainly for estimating their coverage area of base stations located along the railway track for designing future train mobile communication systems. We got associated with them for scientific purpose of getting good data for evaluating models. They adopted the methodology of measuring signal level at every meter and averaging over one hundred meters for their own planning purposes.

Coverage objectives for mobile radio systems utilized by railways are prescribed in technical regulations of International Union of Railways (UIC code leaflet no.751-3) [5]. According to this, satisfactory coverage of an entire line is achieved if a minimum reception signal can be attained over $95 \%$ of the track distance and for $95 \%$ of the time. To estimate this coverage (which is not part of this paper) $100 \mathrm{~m}$ has been chosen as the statistic determined over portion of the path. A train traveling at $60 \mathrm{~km} / \mathrm{hr}$ will pass this gap within 6 seconds. This will keep the communication link up right. In the present study, the interest is to investigate the median path loss and not the fast fading.

The region extending from Meerut to Saharanpur can be classified as open area with intermittent trees and small villages and towns in between. The region extending from Vangani, Neral, and so forth in western India is also open with agricultural lands and the region around the base station is of suburban in nature. Overall both the northern and western regions represent typical rural Indian scenario. Microwave towers located by the track side were utilized as base stations. In the northern region, the terrain is flat and open whereas in the western region where measurements were conducted the terrain is rough with some hilly (ghat) sections in between. Photographs of environments, clutter where measurements were conducted are shown in Figures 1-4 and are described under the radio planning tool section. These are given to get a feel of the environment. 


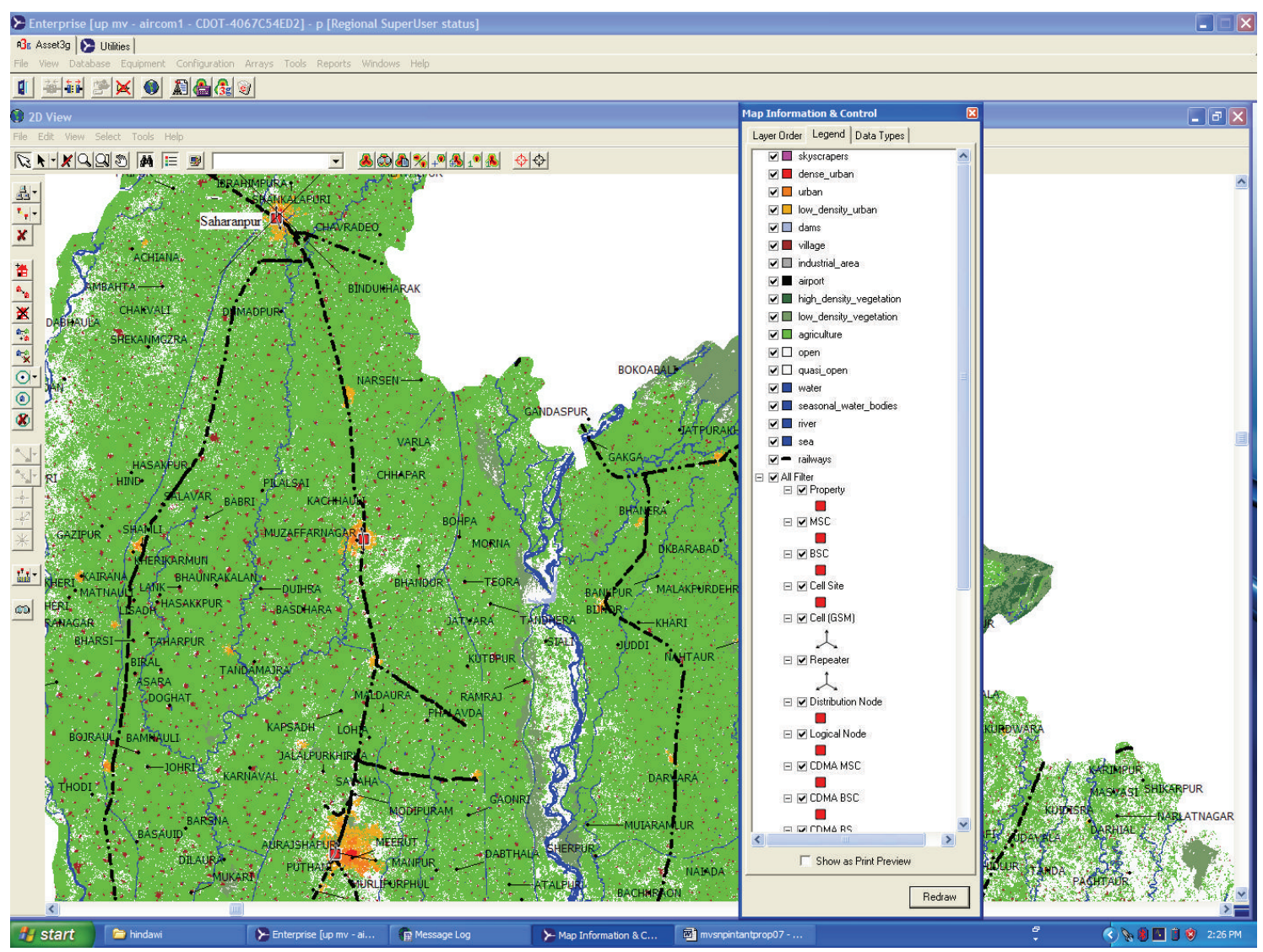

FIgURE 1: Clutter map of north Indian base stations.

\section{RESULTS}

The prediction methods utilized in the present study are (1) Hata [6], (2) Blomquist and Ladell [7], (3) Egli [8], and (4) irregular terrain model [ITM] [9]. The details of prediction methods are not included here and can be obtained from respective references. In this study, the observed signal levels are converted into path losses and compared with the theoretically computed path losses. Instead of describing the comparison of individual base station results with the above prediction methods, statistical indicators like standard deviation and mean error for each prediction method have been deduced and are given in Table 1. These indicators help to evaluate the suitability of the prediction methods.

\subsection{Standard deviations of prediction methods}

Mean errors and standard deviations of the prediction errors for all the methods have been deduced and shown in Table 1.

The general practice in radio wave propagation modeling is that when a given model is exhibiting a highest standard deviation, it is considered not suitable and when it is having a low standard deviation, it is considered suitable in that region. From Table 1, the following observations have been made. In the northern India, Hata's method showed less standard deviation for all the three paths. Hata's method also exhibited less mean error compared with Egli, Blomquist and
Ladell, and ITM methods. The negative sign before mean error shows that the given model is over estimating the path loss. In the case of west Indian paths, Hata's method followed by ITM method gave less standard deviations. Hata's method exhibited higher mean error and higher standard deviations for west Indian paths. This could be due to the difference in terrains between northern and western Indian regions. In the northern region, the terrain was flat, open whereas in west India, it was rough in nature as in the case of Pangoli and Talegaon base stations. In the case of Pune base station where suburban conditions prevailed, all the methods predicted standard deviation within 5-7 dB. Similarly, in the case of Neral base station where there is smooth variation of terrain all the prediction methods yielded a deviation between $4-5 \mathrm{~dB}$. In the case of Pangoli and Talegaon high standard deviations were observed due to the varying and rough nature of terrain.

\subsection{Investigation by diffraction mechanism}

Rec-526 of ITU-R [10] is used to investigate propagation by diffraction and knife edge diffraction. Since no mountains and hills are there along the path knife edge diffraction has not been utilized. Only spherical diffraction has been used. No corrections are used for vegetation. The terrain is flat with rolling plains along the track and not much vegetation is seen. We made an attempt to compute the losses due to 


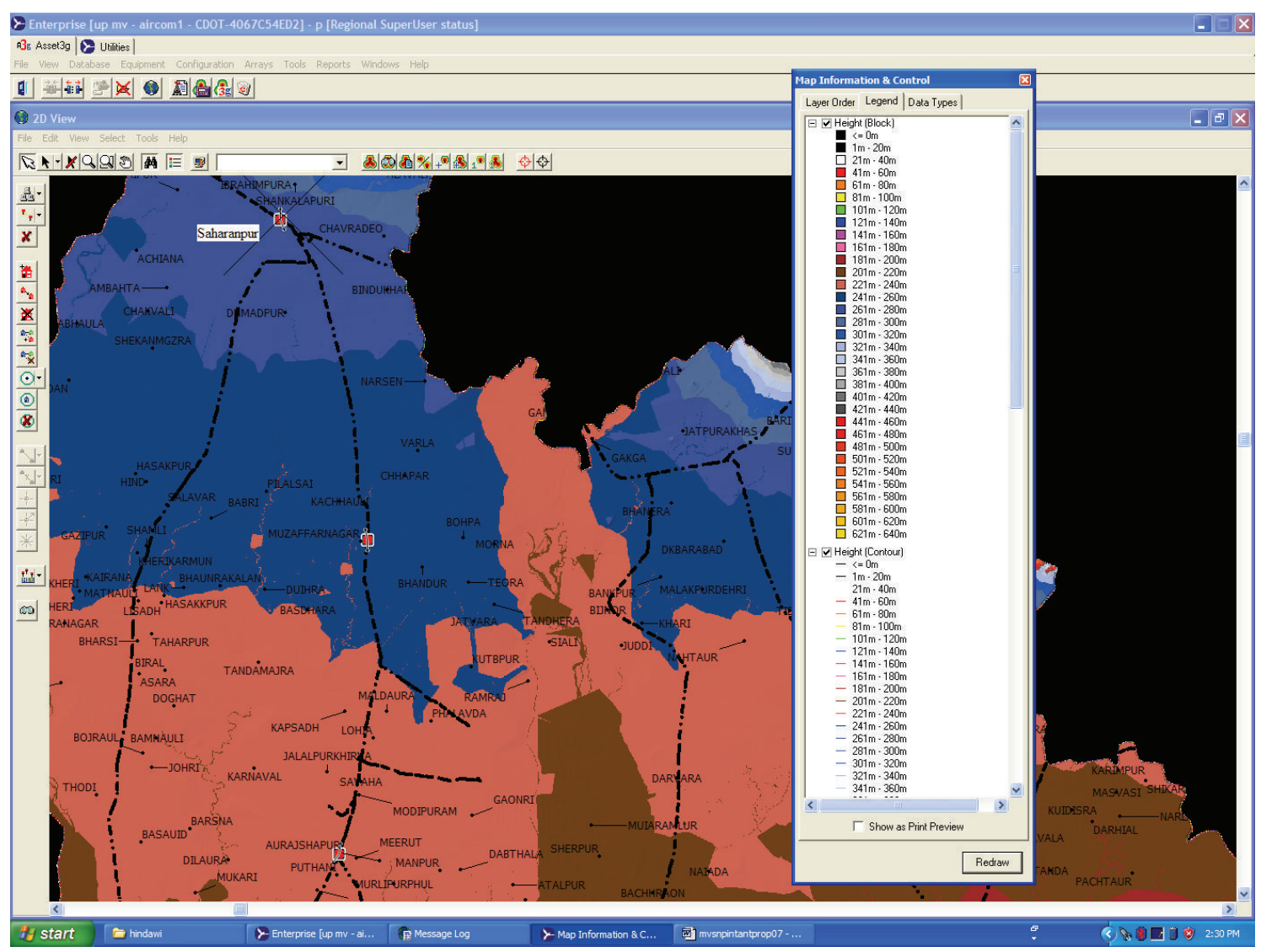

FIGURE 2: Terrain variation of north Indian base stations.

diffraction using the above Rec-526 for various paths beyond the line-of-sight distances. The losses obtained and their comparison with measured losses are given in Table 2. In the table, distances are in $\mathrm{km}$ and losses are in $\mathrm{dB}$.

Here diffraction losses are computed for distances beyond line-of-sight zones. For each path a radio horizon distance has been computed and beyond this distance diffraction losses have been deduced. A perusal of the above table indicates that in the case of north Indian paths, Meerut base station exhibited deviation of 10-15 dB, Muzzafarnagar exhibiting 10-18 dB, and Saharanpur base station showing a deviation of $12-15 \mathrm{~dB}$. These large deviations show that signal propagation at these distances is not supported by diffraction mechanism. In the case of west Indian paths Pangoli and Talegaon base stations exhibited large deviations of the order of $20 \mathrm{~dB}$ and above. Only Pune base station where only two experimentally measured values are available beyond the los zone, some kind of agreement is seen between diffraction computed and measured path losses. Probably only in this case beyond $30 \mathrm{~km}$ propagation occurred through diffraction mechanism.

\subsection{Investigations with radio planning tool}

Using the digital terrain data with a resolution of $50 \mathrm{~m}$ and Aircom's asset tool [11] clutter, terrain and environmental photographs, signal coverage plots for different base stations have been generated. Clutter maps, terrain maps for entire northern and western base stations are shown in Figures 1-4. Figure 1 shows the clutter map of north Indian base stations Meerut, Muzaffarnagar, and Saharanpur base stations along the track. Meerut base station is surrounded by low density urban environment. As one moves along the track from Meerut to Muzaffarnagar base station, agricultural lands and very low density vegetation are seen. At intermittent distances rural villages are located. From Muzzafarnagar base station to Saharanpur base station also agricultural lands along with rural features are seen. All the base stations are surrounded by low density urban environment up to small distances. Figure 2 depicts the terrain variation of these north Indian base stations. Meerut base station is situated at a distance of $225 \mathrm{~m}$ above mean sea level, Muzaffarnagar situated at a height of $243 \mathrm{~m}$ above mean sea level, and Saharanpur located at a height of $275 \mathrm{~m}$ above mean seal level. As one progresses, the terrain is rising and there is a gradual upward slope.

Figure 3 shows the clutter map of west Indian base stations Vangani, Neral, Karjat, Pangoli, Talegaon, and Pune. From Vangani to Neral, open regions with low density vegetation are seen along the track. Similar environment between Neral to Karjat is seen. From Karjat to Pangoli open area with low height vegetation is seen. This is not tall enough to block out radio waves and apply foliage losses. The region between Pangoli and Talegaon is filled with 


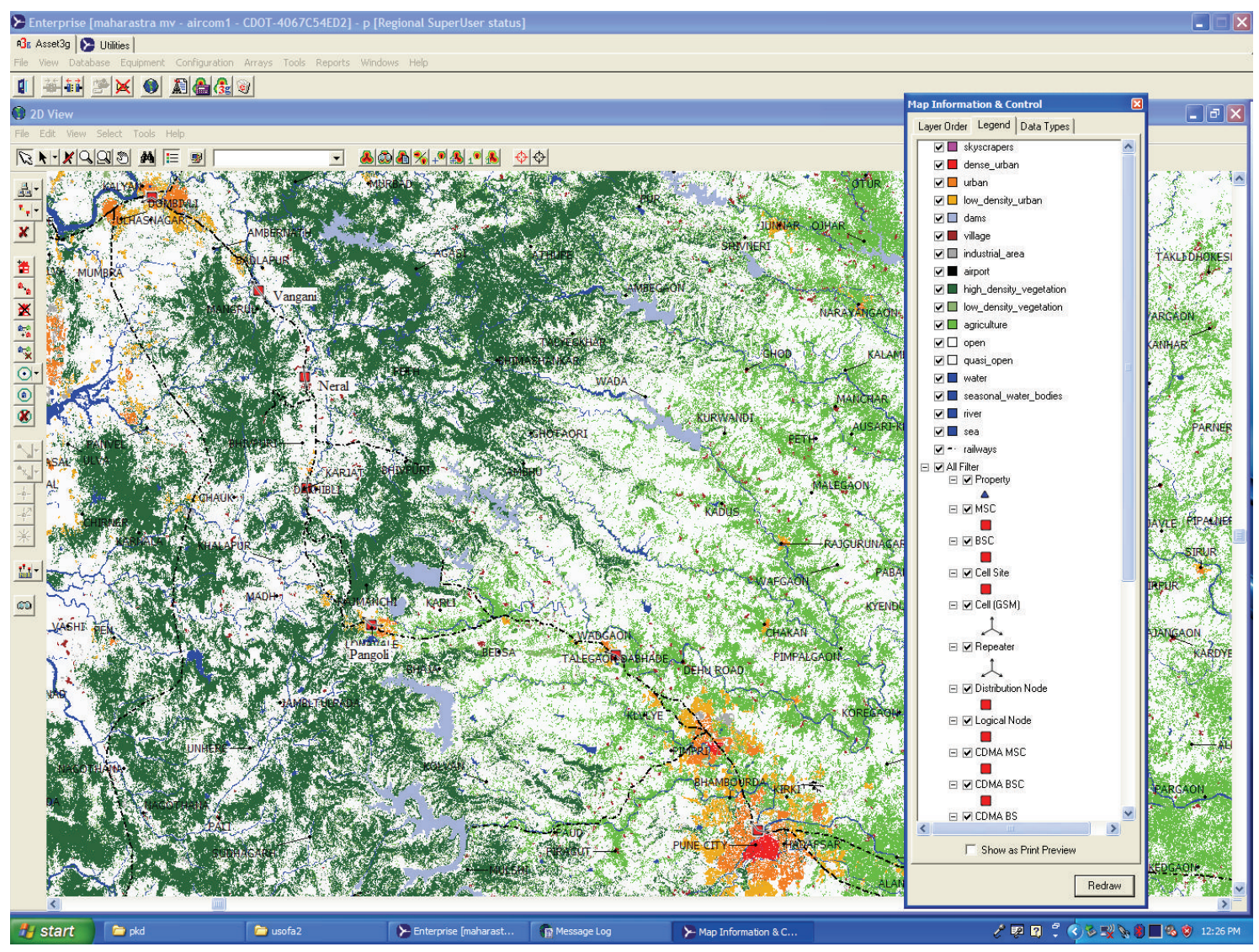

Figure 3: Clutter map of west Indian base stations.

TABLe 1: Mean errors (me) and standard deviations (sd) of all the prediction methods (dB).

\begin{tabular}{|c|c|c|c|c|c|c|c|c|}
\hline \multirow{2}{*}{ Base station } & \multicolumn{2}{|c|}{ Hata } & \multicolumn{2}{|c|}{ Egli } & \multicolumn{2}{|c|}{ Blomquist } & \multicolumn{2}{|c|}{ ITM } \\
\hline & me & sd & me & $\mathrm{Sd}$ & me & $\mathrm{sd}$ & me & sd \\
\hline Meerut & -1.36 & 3.23 & -12.97 & 3.85 & -4.10 & 4.44 & 1.72 & 4.10 \\
\hline Muzafarnagar & -2.57 & 5.55 & -10.97 & 19.33 & -2.20 & 18.0 & 3.68 & 17.02 \\
\hline Saharanpur & -1.81 & 3.12 & -14.47 & 4.52 & -5.44 & 5.47 & 1.23 & 5.42 \\
\hline Vangani & -9.10 & 11.55 & 0.26 & 21.00 & 14.76 & 19.2 & 15.2 & 24.68 \\
\hline Neral & 9.99 & 5.01 & 1.28 & 4.6 & 15.98 & 4.37 & 17.55 & 5.3 \\
\hline Karjat & 4.96 & 4.52 & 7.38 & 7.71 & 21.02 & 7.23 & 23.43 & 8.64 \\
\hline Pangoli & -16.17 & 11.83 & -27.63 & 11.52 & -16.33 & 12.86 & -13.33 & 12.28 \\
\hline Talegaon & -3.2 & 9.92 & -3.12 & 8.67 & -2.66 & 8.87 & -2.26 & 9.13 \\
\hline Pune & 0.31 & 5.74 & -10.65 & 6.17 & 3.53 & 6.31 & 7.54 & 5.95 \\
\hline
\end{tabular}

moderate agricultural lands and partly open regions. From Pangoli onwards the railway track enters the hilly terrain. The region between Talegaon and Pune is also open and agricultural region. Near Pune base station low density urban environment is seen. Figure 4 shows the terrain variation of all these west Indian base stations. Vangani is situated at a height of $40 \mathrm{~m}$ above mean sea level, Neral at $40 \mathrm{~m}$, Karjat at $80 \mathrm{~m}$, and Pangoli at $600 \mathrm{~m}$. There is a steep upward slope towards Pangoli. At Talegaon, the mean sea level height is $600 \mathrm{~m}$ and at Pune the corresponding value is $560 \mathrm{~m}$.

\subsubsection{Propagation model}

The propagation model employed in this tool [11] is illustrated as follows.

$$
\begin{aligned}
\text { Path loss }= & \mathrm{K} 1+\mathrm{K} 2 \log (d)+\mathrm{K} 4(\mathrm{Hms})+\mathrm{K} 4 \log (\mathrm{Hms}) \\
& +\mathrm{K} 5 \log (\text { Heff })+\mathrm{K} 6 \log (\text { Heff }) \log (d) \\
& +\mathrm{K} 7(\text { diffn })+\text { Clutter Loss }
\end{aligned}
$$




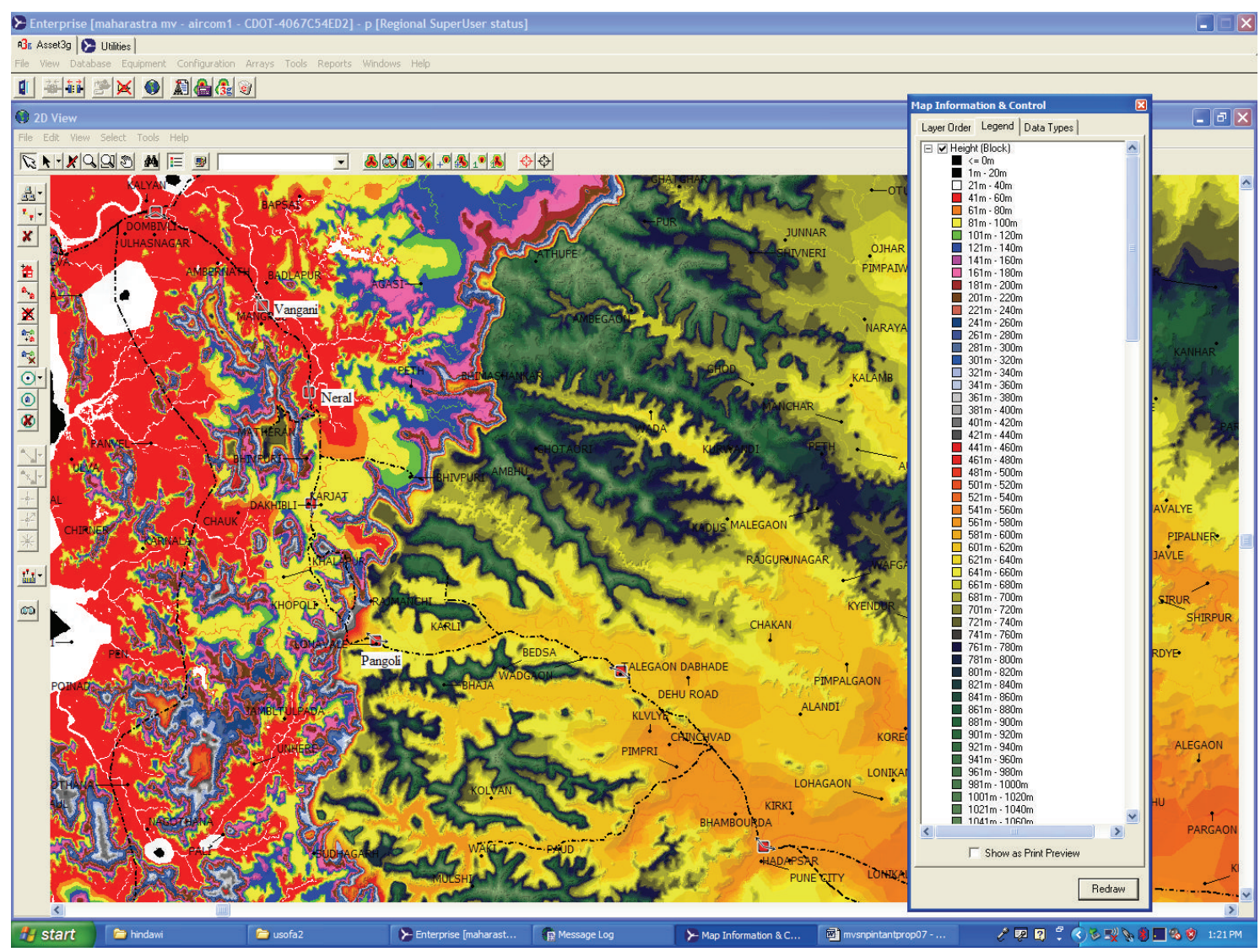

FIGURE 4: Terrain variation of west Indian base stations.

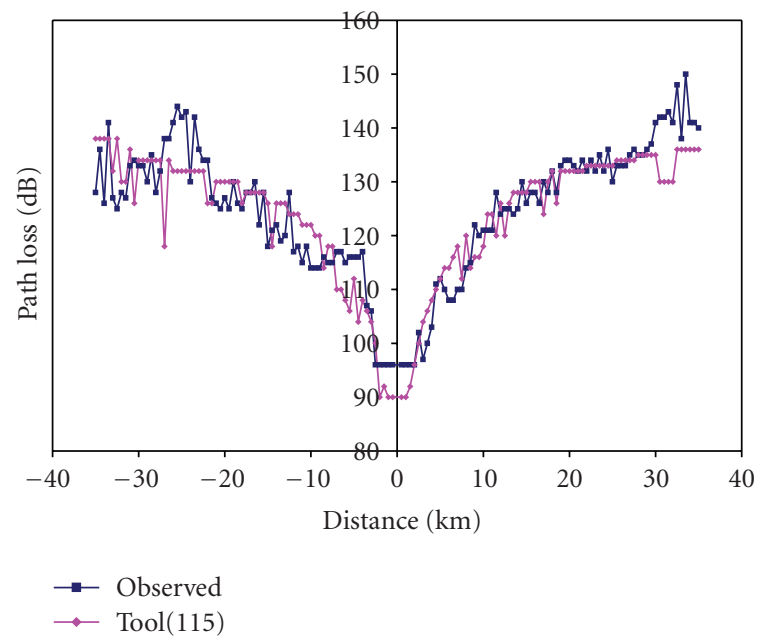

FIgURE 5: Comparison of tool predicted losses with observed losses versus track distance for Meerut base station.

where $d$ is distance between base to mobile station $(\mathrm{Km})$; Hms is height of the mobile station above ground (meter). This figure may be specified either globally or for individual clutter categories. Heff is effective base station antenna height (meter). Diffn is diffraction loss calculated using Epstein, Peterson, Deygout, or Bullington equivalent knife

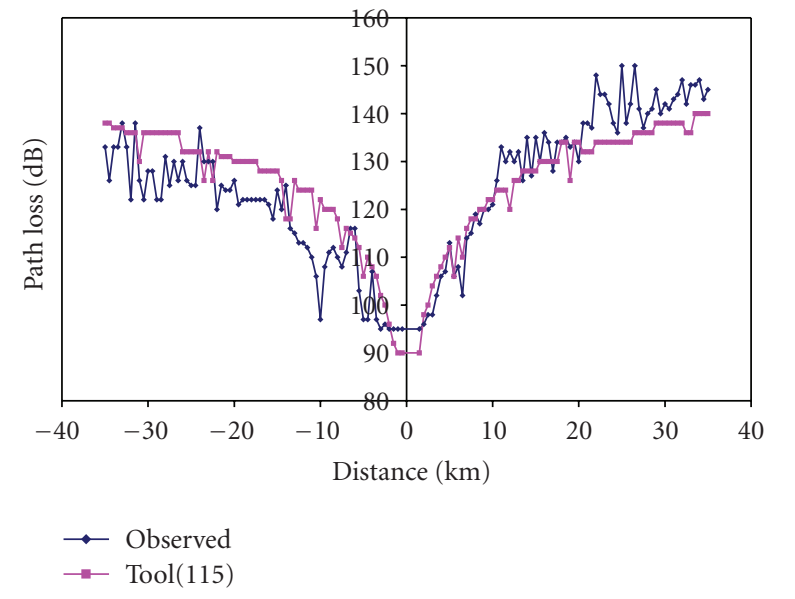

FIGURE 6: Comparison of tool predicted losses with observed losses versus track distance for Muzaffarnagar base station.

edge methods. $\mathrm{K} 1$ and $\mathrm{K} 2$ are intercept and slope. These factors correspond to a constant offset (in $\mathrm{dBm}$ ) and a multiplying factor for the log of the distance between the base station and mobile. K4 is mobile antenna height factor. It is a correction factor used to take into account the effective mobile antenna height. K4 is Okumura-Hata multiplying 
TABLE 2: Computed and observed diffraction losses for north and west Indian paths (dB).

\begin{tabular}{|c|c|c|c|c|c|c|c|c|}
\hline \multicolumn{9}{|c|}{ North Indian paths } \\
\hline & Meerut & & \multicolumn{3}{|c|}{ Muzzafarnagar } & \multicolumn{3}{|c|}{ Saharanpur } \\
\hline Dis $(\mathrm{km})$ & $\begin{array}{l}\text { Obs loss } \\
(\mathrm{dB})\end{array}$ & $\begin{array}{l}\text { Diff loss } \\
(\mathrm{dB})\end{array}$ & Dis $(\mathrm{km})$ & $\begin{array}{l}\text { Obs loss } \\
(\mathrm{dB})\end{array}$ & $\begin{array}{l}\text { Diff loss } \\
\quad(\mathrm{dB})\end{array}$ & Dis $(\mathrm{km})$ & $\begin{array}{c}\text { Obs loss } \\
(\mathrm{dB})\end{array}$ & $\begin{array}{c}\text { Diff loss } \\
(\mathrm{dB})\end{array}$ \\
\hline 32.5 & 129.5 & 144.6 & 32.5 & 126.5 & 144.6 & 32.5 & 130 & 144.6 \\
\hline 35 & 130 & 146.8 & 35 & 127.5 & 146.8 & 35 & 135 & 146.8 \\
\hline 37.5 & 133 & 148.9 & 37.5 & 128 & 148.9 & 37.5 & 135 & 148.9 \\
\hline 40 & 135 & 150.5 & 40 & 136 & 150.5 & 40 & 139 & 150.5 \\
\hline 42.5 & 140 & 151.9 & 42.5 & 141 & 151.9 & 42.5 & 140 & 151.9 \\
\hline 45 & 143.5 & 153.8 & 45 & 142 & 153.8 & 45 & 141.5 & 153.8 \\
\hline 47.5 & 144 & 157 & 47.5 & 144 & 157 & 47.5 & 142 & 157 \\
\hline 50 & 145 & 158.4 & 50 & 143.5 & 158.4 & & & \\
\hline \multicolumn{9}{|c|}{ West Indian Paths } \\
\hline & Pangoli & & & Talegoan & & & Pune & \\
\hline Dist. (km) & $\begin{array}{l}\text { Obs. loss } \\
(\mathrm{dB})\end{array}$ & $\begin{array}{l}\text { diff. loss } \\
(\mathrm{dB})\end{array}$ & Dist. (km) & $\begin{array}{l}\text { Obs. loss } \\
(\mathrm{dB})\end{array}$ & $\begin{array}{l}\text { diff. loss } \\
(\mathrm{dB})\end{array}$ & Dist. $(\mathrm{km})$ & $\begin{array}{l}\text { Obs. loss } \\
(\mathrm{dB})\end{array}$ & $\begin{array}{c}\text { diff. loss } \\
(\mathrm{dB})\end{array}$ \\
\hline 31 & 122 & 142.5 & 30 & 140 & 127 & 31.5 & 136 & 142 \\
\hline 32 & 118 & 142.6 & 32.5 & 156 & 128 & 33 & 145 & 143.3 \\
\hline 33 & 141 & 143.3 & & & & & & \\
\hline 34 & 139 & 143.9 & & & & & & \\
\hline 35 & 135 & 144.5 & & & & & & \\
\hline 36 & 126 & 145.6 & & & & & & \\
\hline 38 & 115 & 147 & & & & & & \\
\hline 40 & 110 & 148.5 & & & & & & \\
\hline 42 & 114 & 150 & & & & & & \\
\hline 44 & 107 & 150.3 & & & & & & \\
\hline 45 & 127 & 151.5 & & & & & & \\
\hline
\end{tabular}

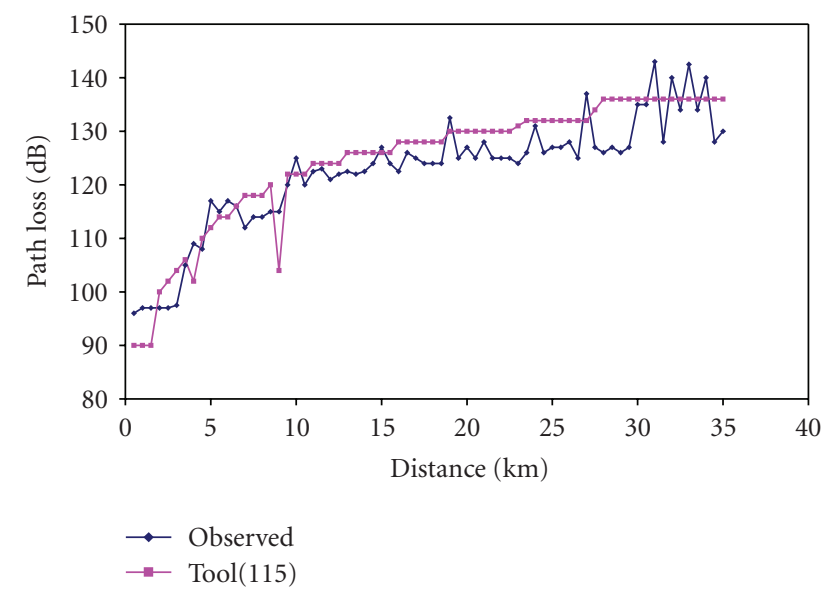

FIGURE 7: Comparison of tool predicted losses with observed losses versus track distance for Saharanpur base station.

factor for Hms. K5 is effective antenna height gain. This is the multiplying factor for the log of the effective antenna height K6. This is the Okumura-Hata type multiplying factor for $\log$ (Heff) $\log (d)$. K7 takes into account diffraction effects. A choice of diffraction methods is available.

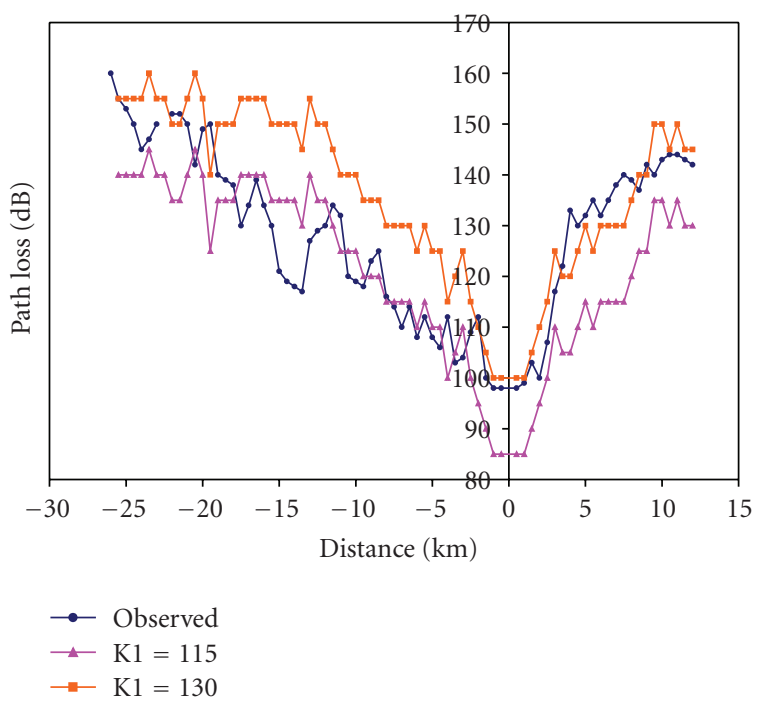

Figure 8: Comparison of tool predicted losses with observed losses versus track distance for Vangani base station.

Closs is clutter specifications such as heights and separation that are also taken into account in the calculation process. Clutter losses shown in Table 3 have been obtained 


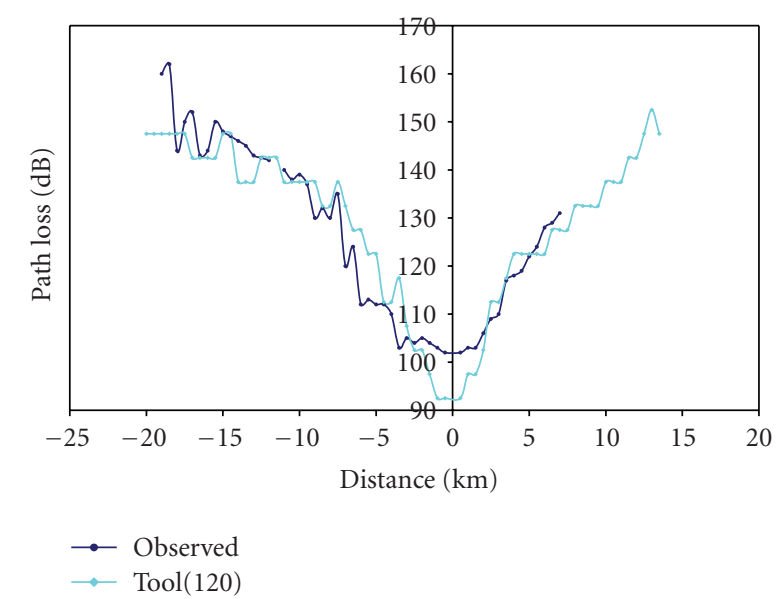

Figure 9: Comparison of tool predicted losses with observed losses versus track distance for Neral base station.

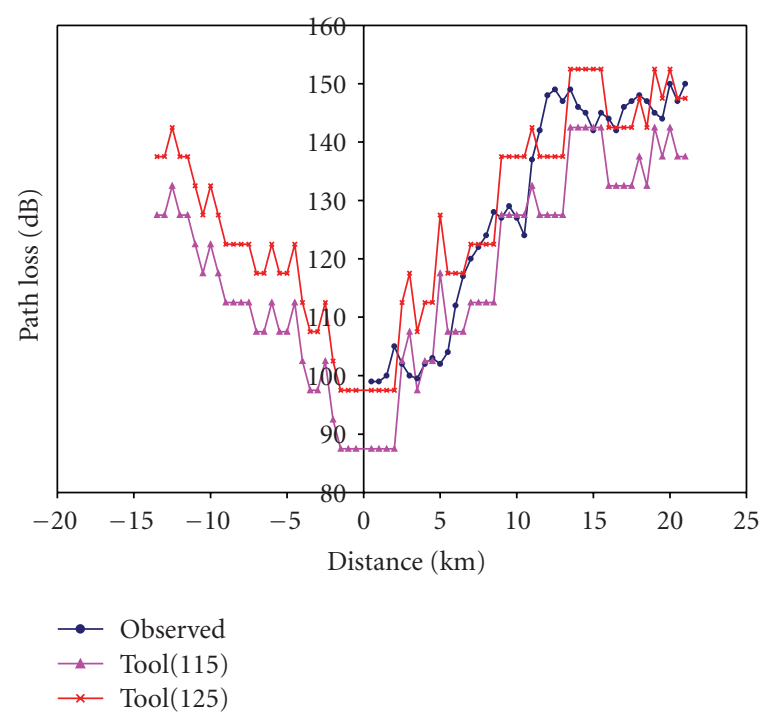

FIGURE 10: Comparison of tool predicted losses with observed losses versus track distance for Karjat base station.

based on our past experiences of conducting radio measurements in Indian rural zones. Low density urban $=1 \mathrm{~dB}$, village $=1 \mathrm{~dB}$, high density vegetation $=4 \mathrm{~dB}$, low density vegetation $=1 \mathrm{~dB}$, agriculture $=0 \mathrm{~dB}$, open area $=-5 \mathrm{~dB}$, quasiopen $=-5 \mathrm{~dB}$, and water $=-15 \mathrm{~dB}$. The parameters of the tool at various frequencies are shown in Table 3.

From Table 3, it is seen that $\mathrm{K} 2$ is independent of frequency. Keeping K2 to K7 values corresponding to $450 \mathrm{MHz}$ (this being nearest to $320 \mathrm{MHz}$ in the present study), an attempt has been made to tune the value of $\mathrm{K} 1$ with the help of measured values. Various values of K1 corresponding to different paths are deduced and signal coverage plots for various base stations have been generated. In these entire figures, tool generated values are confined to distances of $35 \mathrm{~km}$. This is due to the inherent limit set in the tool by the manufacturer when it is being used in GSM mode. Comparison of tool predicted losses for various values of

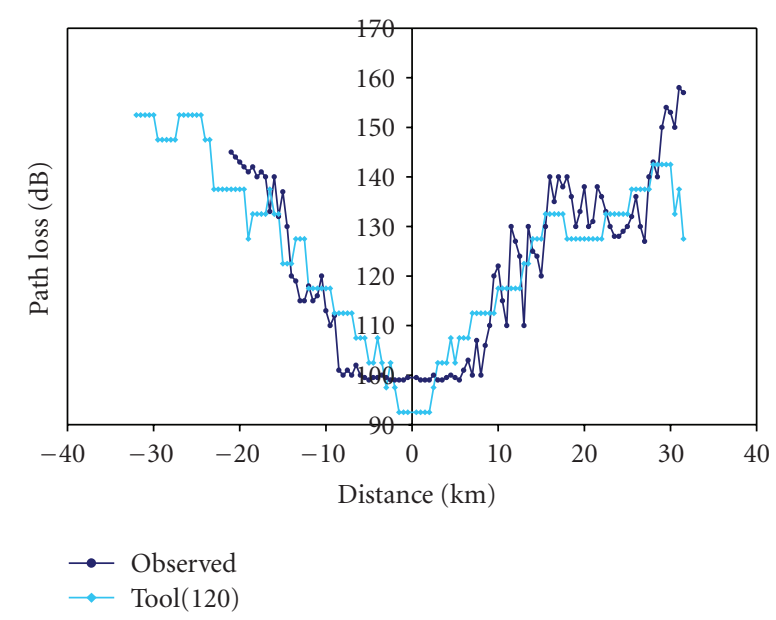

FIgURE 11: Comparison of tool predicted losses with observed losses versus track distance for Talegaon base station.

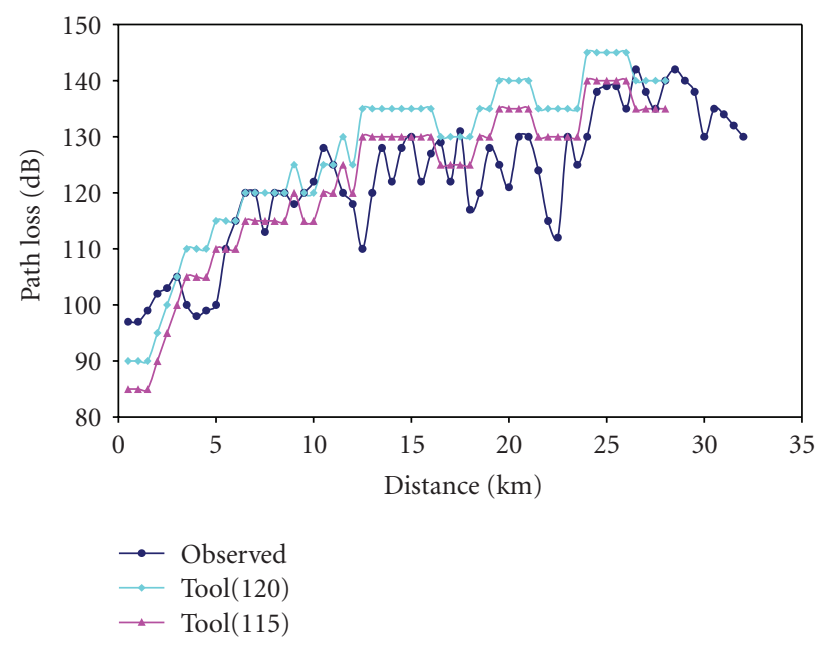

FIGURE 12: Comparison of tool predicted losses with observed losses versus track distance for Pune base station.

K1 with measured losses is shown in Figures 5, 6, and 7 for north Indian base stations and in Figures 8, 9, 10, 11, and 12 for west Indian base stations. The figure for Pangoli base station is not shown due to restriction of number of figures. The advantage of these tuned values over these regions is that these can be used by the future operators of mobile communications for this and similar regions.

\subsubsection{Comparison of tool predicted values with observed losses}

In the figures, measured data have been processed in accordance with the resolution of the prediction tool. Figures 5,6 , and 7 show the comparison of tool predicted values of north Indian base stations Meerut, Muzaffarnagar, and Saharanpur with measured values as a function of track distance. The tool has been utilized to optimize the value 
TABLE 3: Parameters of the Aircom tool at various frequencies.

\begin{tabular}{lcccc}
\hline Parameter & $450 \mathrm{MHz}$ & $900 \mathrm{MHz}$ & $1800 \mathrm{MHz}$ & $2000 \mathrm{MHz}$ \\
\hline Mobile Rx height(m) & 1.5 & 1.5 & 1.5 & 8493 \\
Earth radius(Km) & 8493 & 8493 & 160.9 & 8493 \\
K1 & 142.3 & 150.6 & 44.9 & 162.5 \\
K2 & 44.9 & 44.9 & -2.55 & 44.9 \\
K4 & -2.6 & -2.55 & 0 & -2.55 \\
K4 & -8 & 0 & -13.82 & 0 \\
K5 & -11.7 & -13.82 & -6.55 & -13.82 \\
K6 & -4.3 & -6.55 & 0.8 & -6.55 \\
K7 & 0.4 & 0.7 & 0.8 \\
\hline
\end{tabular}

TABLE 4: Standard deviations and mean errors of the predictions of radio planning tool $(\mathrm{dB})$.

\begin{tabular}{|c|c|c|c|c|c|c|c|c|c|c|}
\hline Station & me110 & sd110 & me115 & sd115 & me120 & sd120 & me125 & sd125 & me130 & sd130 \\
\hline Meerut & & & 0.72 & 5.32 & & & & & & \\
\hline Muzzafarnagar & & & -1.23 & 6.92 & & & & & & \\
\hline Saharanpur & & & -2.04 & 4.42 & & & & & & \\
\hline Vangani & & & 6.01 & 10.66 & & & & & -8.99 & 10.66 \\
\hline Neral & & & & & -2.03 & 20.87 & & & & \\
\hline Karjat & & & 6.92 & 7.62 & & & -3.08 & 7.54 & & \\
\hline Pangoli & -13.11 & 17.37 & & & -23.11 & 17.37 & & & & \\
\hline Talegaon & & & & & 0.72 & 7.93 & & & & \\
\hline Pune & & & -1.32 & 7.62 & -6.15 & 7.32 & & & & \\
\hline
\end{tabular}

of K1. The agreement between measured and tool predicted values is reasonable. The tool predicted values of path loss for $\mathrm{K} 1=115$ show good coincidence with average values of observed path loss over northern India and this is considered as an optimally tuned value. This is basically due to similarity in type of environment and terrain for all the base stations.

Figures $8,9,10,11$, and 12 depict the comparison of tool predicted values with measured values of path loss for west Indian base stations of Vangani, Neral, Karjat, Talegaon, and Pune base stations. In these figures, the tool has been utilized to optimize the $\mathrm{K} 1$ ranging from 110 to 130 depending on the individual base station. The evaluation of the suitability of tool mean prediction error and standard deviations for various $\mathrm{K} 1$ values is shown in Table 4.

\section{Standard deviations of the predicted errors from the tool}

The standard deviations and mean error of the prediction errors of the tool are deduced and shown in Table 4 .

In Table 4, me is mean error, sd is standard deviation; 110,115 , and so forth indicate the values of K1. In the case of north Indian stations for $\mathrm{K} 1=115$, Saharanpur exhibits the lowest value of standard deviation $4.4 \mathrm{~dB}$ and the deviation over north varies from 4.4 to 6.9. In the case of west Indian paths, the standard deviation varies from 7.3 to 20.87 , with Pune base station exhibiting the lowest value of standard deviation. Vangani base station was tuned for K1 values of 115 and 130, Karjat for 115 and 125, and Pune for 115 . The two values of $\mathrm{K} 1$ seen are due to the slightly change in environment type on the two sides of each base station. Similarly base stations, Neral tuned for K1 value of 120, Pangoli for 110 and 120, and Talegaon for 120. When the environment is of rolling plains with open type like typical north Indian and in some parts of west India, K1 value of 115 seems to be the optimally tuned value. For rough terrain, K1 value of 125 or 130 can be a better value. High standard deviations reported for Pangoli and other base stations could be due to the rough nature of the terrain. If the standard deviation of Hata's method in Table 1 is compared with standard deviation of tool, it seems that Hata's method still gives marginally better values except for Vangani base station.

\section{CONCLUSIONS}

The main advantage of this comparison with various prediction methods whether empirical or semiempirical is the possible extrapolation of these measurements to similar environments in the related band of frequencies and different base station antenna heights. In the rural/suburban areas, the cellular operators are generally under the notion that same prediction technique holds good in every region of the country. The study showed that different prediction methods yielded different degrees of prediction errors in northern and western zones. In the northern region, Hata's method showed a standard deviation of 3-5dB, Blomquist and Ladell's method showed 4-5 dB except for Muzzafarnagar base station where large standard deviation is seen. ITM and Egli's methods showed small standard deviations for Meerut 
and Saharanpur paths and showed high value of deviation for Muzzafarnagar path. In the western region, Hata's method showed 5-11 dB, ITM showed 6-24dB, Blomquist and Ladell's method showed 5-19 dB, Egli's method showed 5$21 \mathrm{~dB}$. It seems that prediction models along rural railroads give good agreement when the base station antenna is located on the top of the building or hill giving fairly good los distance to many points. In the non-los zone, accuracy becomes less and correction terms become necessary [12]. It seems that Rec-526 of ITU-R method for spherical diffraction is unable to explain the observed losses in the diffraction region satisfactorily.

Using Aircom's asset radio planning tool and digital terrain data, coverage plots for all the base stations have been generated and the intercept factor K1 has been tuned. Photographs of clutter and environment have also been presented. In the case of north Indian base stations, a uniform value of $\mathrm{K} 1=115$ is found to be suitable in explaining the observed results due to the smooth nature of terrain. In the case of west Indian paths, due to the rough nature of terrain two or three values of K1 ranging from 115 to 130 are required in explaining the observed results. The highlight of the present study is deducing optimally tuned values of K1 using Aircom's asset radio planning tool. These results can be utilized for designing future communication systems and for wave propagation modeling over developing countries in similar environment type regions. In the future study, the modified parameters of the radio planning tool can be utilized to predict the signal levels/path losses in these regions and can be compared to future datasets which will be generated in this region at various frequencies.

\section{REFERENCES}

[1] R. Hincapie, J. Sierra, and R. Bustamante, "Remote locations coverage analysis with wireless mesh networks based on IEEE 802.16 standard," IEEE Communications Magazine, vol. 45, no. 1, pp. 120-127, 2007.

[2] A. Medeisis and A. Kajackas, "On the use of the universal Okumura-Hata propagation prediction model in rural areas," in Proceedings of the 51st IEEE on Vehicular Technology Conference (VTC '00), vol. 3, pp. 1815-1818, Tokyo, Japan, May 2000.

[3] N. Blaunstein and Y. Ben-Shimol, "Prediction of frequency dependence of path loss and link-budget design for various terrestrial communication links," IEEE Transactions on Antennas and Propagation, vol. 52, no. 10, pp. 2719-2729, 2004.

[4] M. Miyashita, Y. Serizawa, and T. Terada, "Model selection method for improving path loss prediction of $400 \mathrm{MHz}$ band land mobile radio," in Proceedings of the 62nd IEEE on Vehicular Technology Conference (VTC '05), vol. 2, pp. 13371341, Dallas, Tex, USA, September 2005.

[5] UIC-code 751-3 ORI, "Technical regulations for international ground-train radio systems," 3rd edition 1984, http://www.uic.asso.fr.

[6] M. Hata, "Empirical formula for propagation loss in land mobile radio services," IEEE Transactions on Vehicular Technology, vol. 29, no. 3, pp. 317-325, 1980.

[7] A. Blomquist and L. Ladell, "Prediction and calculation of transmission loss in different types of terrain," in Proceedings of the 20th AGARD Meeting of Electromagnetic Wave Propagation Involving Irregular Surfaces and Inhomogeneous Media, pp. 1-17, The Hague, The Netherlands, March 1974.

[8] J. J. Egli, "Radio propagation above $40 \mathrm{Mc}$ over irregular terrain," Proceedings of the IRE, vol. 45, no. 10, pp. 1383-1391, 1957.

[9] P. L. Rice, A. G. Longley, K. A. Norton, and A. P. Barsis, "Transmission loss predictions for tropospheric communication circuits-Volume I and II," Technical Note 101, Institute for Telecommunication Sciences, Boulder, Colo, USA, 1967.

[10] Rec.ITU-RP.526-9, Propagation by diffraction, International telecommunication union, Geneva, Switzerland .

[11] "Asset 3 g planning tool," http://www.aircominternational .com.

[12] "Wave propagation and radio network planning," http://www .awe-communications.com. 

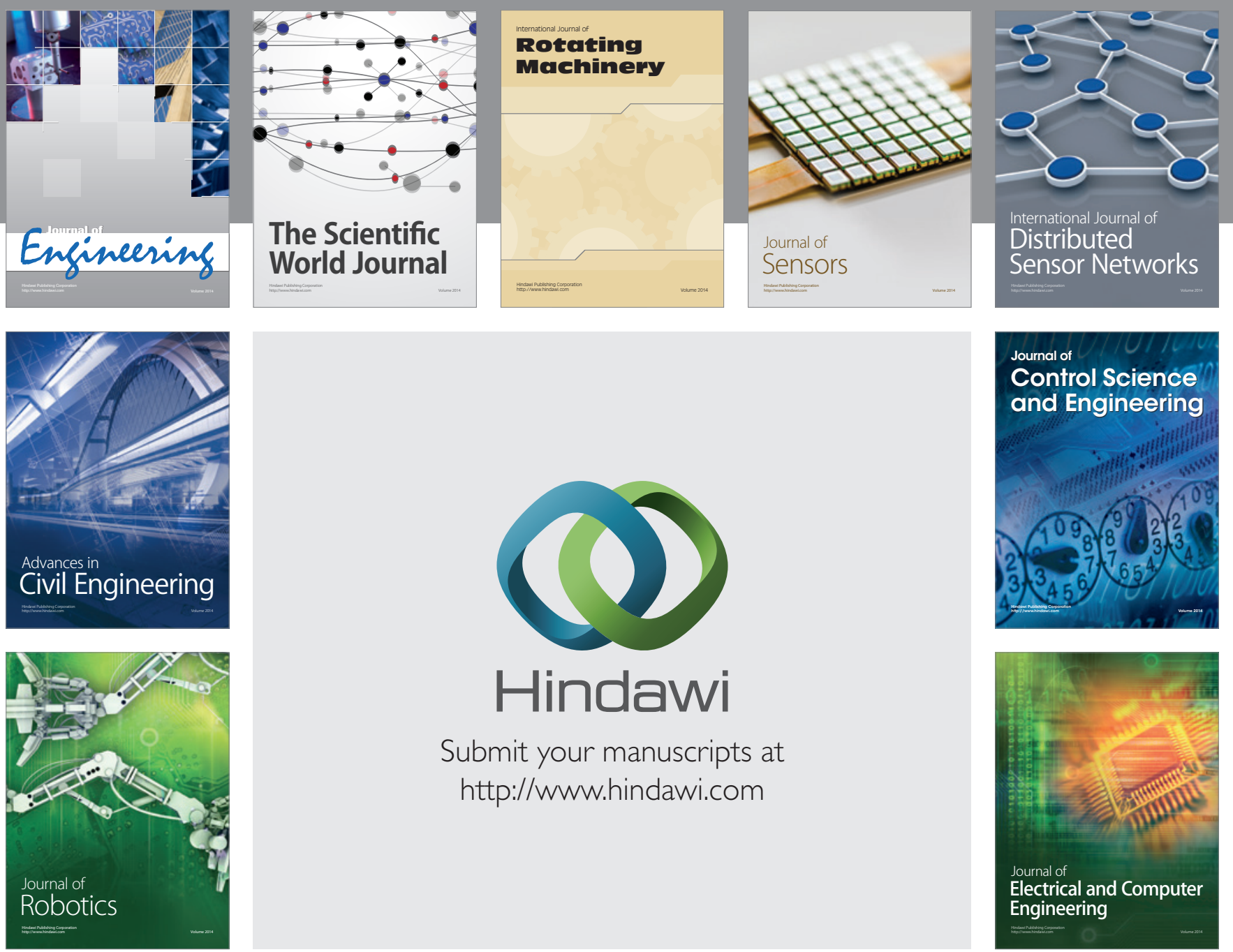

Submit your manuscripts at

http://www.hindawi.com
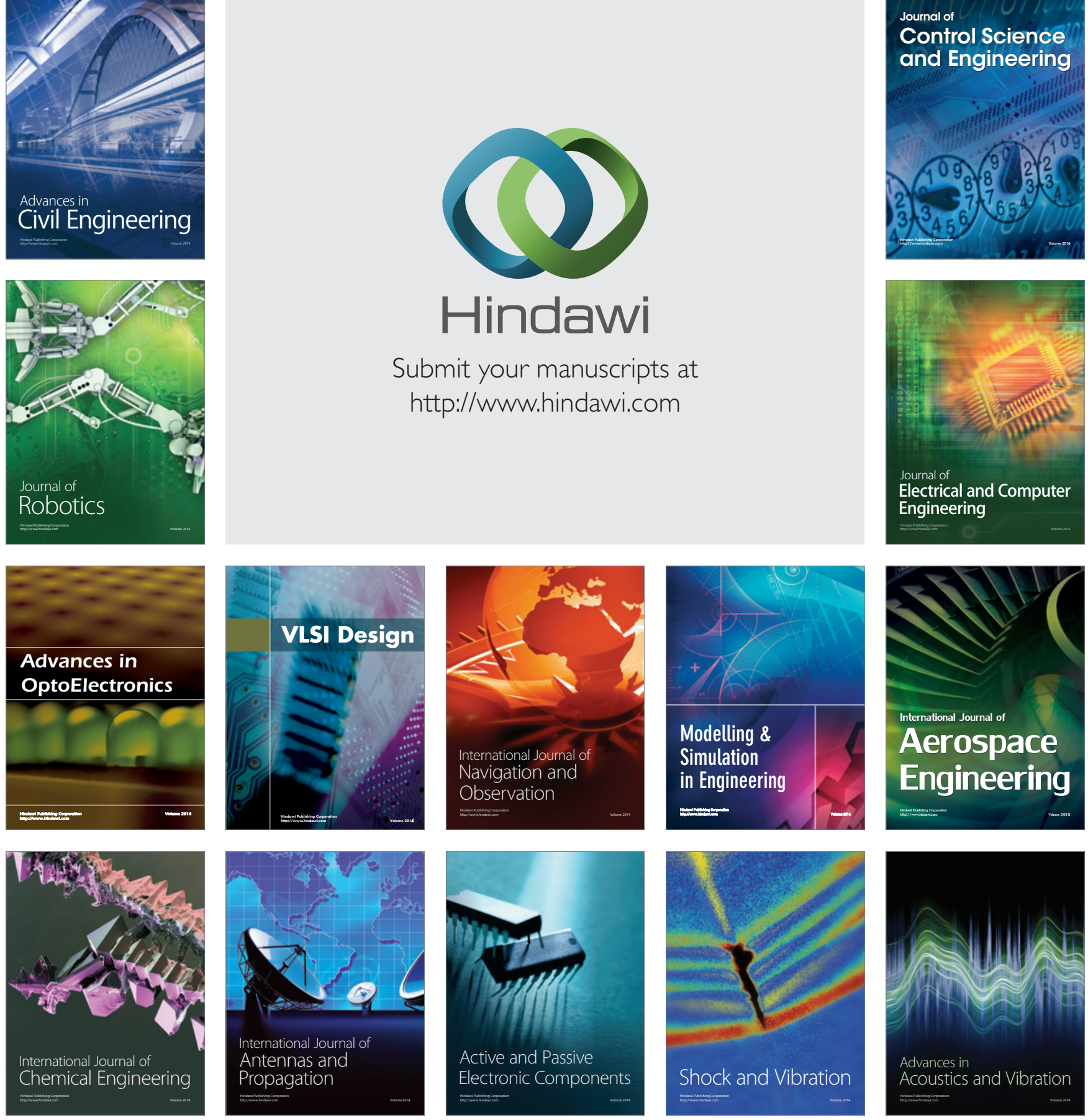